\title{
Tolerância política no Brasil
}

\author{
Ednaldo Ribeiro ${ }^{1}$ (iD \\ Mario Fuks ${ }^{2}$
}

\begin{abstract}
Entendendo a tolerância política como uma das dimensões de uma cultura política democrática, o artigo utiliza um conjunto de dados inéditos produzidos pelo Latin American Public Project para compor, de forma exploratória, um quadro geral sobre essa atitude no contexto nacional. Por meio de técnicas de análise descritivas e multivariadas, identificamos os principais grupos que são alvo de antipatia dos brasileiros e o grau de tolerância em relação a eles, bem como as suas bases demográficas e atitudinais. Os resultados indicam que a manifestação da tolerância é função de atributos tanto sociais (como a geração) quanto atitudinais (como adesão à democracia e interesse por política) e apontam para uma ampla agenda de investigações futuras sobre o tema.
\end{abstract}

Palavras-chaves: tolerância política; grupos alvos de antipatia; Brasil

\section{Introdução ${ }^{3}$}

As eleições presidenciais de 2018 explicitaram a natureza dramática da passionalidade do antagonismo político em nosso país. A polarização expandiu-se para além do âmbito da elite política desde as manifestações e protestos ocorridos a partir de 2013. O conjunto de eventos mais emblemáticos desse processo foram as manifestações e protestos que levaram centenas de milhares de pessoas às ruas entre março de $2015 \mathrm{e}$ julho de 2016, alguns indignados com a corrupção política e pedindo a saída da presidente Dilma Rousseff e outros defendendo a continuidade do governo e o respeito ao resultado das eleições de 2014. Nesses eventos coletivos, eram comuns manifestações verbais, cartazes e faixas com conteúdos que sugeriam padrões de intolerância política. Em alguns casos, esporádicos, essa rejeição se converteu em violência física, o que levou inclusive à construção de um aparato de segurança, semelhante a um muro, separando grupos favoráveis e contrários ao governo no momento em que ocorreram as votações na Câmara

\footnotetext{
1 Departamento de Ciências Sociais da Universidade Estadual de Maringá. Maringá (PR), Brasil.

E-mail: <ednaldoribeiro@icloud.com>.

2 Departamento de Ciência Política da Universidade Federal de Minas Gerais. Belo Horizonte (MG), Brasil. E-mail: <mariofuks@gmail.com>.

${ }^{3}$ Os autores agradecem à Fundação Araucária, CNPq e Capes pelo financiamento da pesquisa que gerou os resultados apresentados neste artigo.
} 
e no Senado sobre a admissibilidade do processo de impeachment da presidente. 0 ambiente virtual proporcionado pelas redes sociais, provavelmente em razão do anonimato, potencializou ainda mais as atitudes de negação à pluralidade de ideias e projetos políticos.

Terminado o processo eleitoral de 2018, o quadro de antagonismo permanece agudo e os episódios de intolerância continuam se repetindo. Se esse cenário, por um lado, é acompanhado de elevação do interesse dos brasileiros por política (efêmero ou não, só o tempo irá dizer), por outro, nos obriga a pensar sobre os seus efeitos sobre a jovem democracia brasileira, em especial sobre a liberdade de expressão e a coexistência da pluralidade de projetos políticos.

Violações dos direitos de minorias são historicamente impetradas por governos que sentem sua posição ameaçada, mas são igualmente relevantes aquelas ameaças mais sutis que operam no nível da opinião pública (Mill, 2007). Atitudes e comportamentos intolerantes podem restringir fortemente o espaço de atuação de minorias, comprometendo a extensão da liberdade (Gibson, 2009). Daí a importância de investigar se, e em que medida, os cidadãos de um determinado país compartilham atitudes favoráveis à formação de um ambiente de debate e competição política, atuando inclusive como freio indispensável contra medidas governamentais restritivas.

Ao investigar a tolerância política, entramos numa dimensão, pouco estudada no Brasil, da cultura política democrática. Seguimos aqui os passos de uma crescente literatura que entende que o apoio à democracia deve ser examinado como um fenômeno que envolve múltiplas dimensões (Booth e Seligson, 2009; Schedler e Sarsfield, 2007; Carlin e Singer, 2011; Fuks et al., 2016) e que, portanto, o "cidadão democrático" não é aquele que apenas afirma preferir a democracia como forma de governo, mas o que também adere a um conjunto de valores e crenças democráticos, do qual a tolerância é parte constitutiva.

O principal objetivo deste artigo é introduzir na agenda de pesquisas sobre comportamento político, no Brasil, a discussão sobre a tolerância política. Em razão dessa natureza inaugural, nossa abordagem é, em grande medida, exploratória. Procuramos principalmente apresentar um quadro geral dessas atitudes em nosso contexto e, quando possível, compará-lo com o de outros países. Quando avançamos na proposição de modelos multivariados para a identificação dos condicionantes da manifestação de atitudes tolerantes, o objetivo é testar efeitos de variáveis clássicas na literatura internacional sobre o assunto, como sexo, escolaridade, idade e interesse por política, além de outras que apresentam relevância específica em nosso contexto.

O material empírico utilizado é inédito para o contexto nacional e foi produzido pelo Barômetro das Américas em sua onda de 2017. Infelizmente o alcance comparativo do presente artigo é limitado, pois a bateria de questões sobre tolerância política foi aplicada apenas para a amostra brasileira. Os dados são analisados por meio de técnicas descritivas e multivariadas de análise estatística, todas conduzidas no ambiente $\mathrm{R}$ de programação. 
O presente artigo é composto por quatro seções, além desta Introdução. A primeira delas, "Medidas e condicionantes da tolerância política", apresenta essa agenda de estudo, passando pelos elementos mais importantes de sua trajetória de desenvolvimento, destacando especialmente a evolução dos procedimentos de mensuração da tolerância política. A segunda seção, "Dados e metodologia", apresenta informações sobre o material empírico inédito utilizado e os procedimentos metodológicos empregados. A terceira seção, "A antipatia e a tolerância política no Brasil", expõe um conjunto de estatísticas descritivas com o objetivo de compor um quadro geral das atitudes de tolerância entre a população brasileira, indicando os principais grupos-alvo e a intensidade dessas disposições. Na quarta seção, "Os condicionantes da tolerância política", procuramos explorar possíveis explicações para a manifestação de atitudes tolerantes, testando efeitos de variáveis clássicas presentes na literatura internacional.

\section{Medidas e condicionantes da tolerância política}

Nos marcos da democracia contemporânea, tolerância política pode ser definida como o resultado do acesso legalmente garantido ao livre mercado de ideias de todas as ideologias ou projetos políticos existentes (Gibson, 2009). Excluídas as ideias que pregam violência, mesmo grupos que defendem projetos considerados não conformistas pela ideologia dominante, como os comunistas na época em que Stouffer (1955) conduziu seu estudo pioneiro, deveriam ser tolerados em contextos democráticos. No campo do comportamento político, a tolerância se refere à atitude de aceitação da fruição de direitos políticos pelos grupos com os quais o indivíduo manifesta forte discordância de projeto político (Sullivan, Piereson e Marcus, 1982). Nesse sentido, a tolerância política se diferencia da tolerância social e do preconceito (Gibson, 2009), já que pressupõe muito mais do que a ausência de estereótipos negativos baseados em características físicas ou elementos culturais e pode existir mesmo na presença destes. Um dos principais preditores da intolerância política, como vamos argumentar mais adiante, é a percepção de ameaça individual e sociotrópica gerada pelo grupo de discordância (Sullivan, Piereson e Marcus, 1982). Sendo assim, um indivíduo preconceituoso em relação a certo grupo, mas que não percebe os seus membros como perigosos ou ameaçadores em termos políticos, provavelmente não apresentaria atitudes intolerantes.

Para lidar com a tolerância como objeto de investigação empírica, a primeira tarefa é identificar a quem ela se dirige. O estudo pioneiro de Stouffer (1955), realizado no contexto do macarthismo norte-americano, lidava com a prevalência de uma ameaça ideológica única, o comunismo. A dificuldade cresce exponencialmente quando se amplia o universo dos grupos que são alvos de intolerância. O General Social Survey, principal fonte de dados sobre o tema nos Estados Unidos, por exemplo, inclui em seu levantamento cinco grupos: ateus, comunistas, homossexuais, militaristas e racistas (Smith et al., 2016).

Para Sullivan, Piereson e Marcus (1982), o problema dessas abordagens é que elas 
não levaram em consideração uma questão conceitual que tem importante consequência empírica: a intolerância só pode ocorrer quando um indivíduo tem atitudes negativas em relação a um determinado grupo. Segundo os autores, ao limitarem os alvos da tolerância a determinados grupos impopulares, essas abordagens correm o risco de medir a tolerância de apenas parte da população.

Isso ocorre porque a escolha do grupo de antipatia está intimamente associada à ideologia do indivíduo; ou seja, ela não é aleatória. Segundo Sullivan, Piereson e Marcus (1982), os estudos clássicos de tolerância tinham como foco grupos de esquerda (especialmente, os comunistas). Nessas pesquisas as perguntas eram diretas, mencionando o grupo não conformista e pedindo para o entrevistado se posicionar a respeito dos direitos políticos dos seus membros.

Devido a esse viés, os estudos clássicos: 1) identificaram, de forma equivocada, um aumento de tolerância política nas duas décadas que se seguiram ao estudo de Stouffer, já que os comunistas deixaram de ser o alvo quase exclusivo de intolerância nos EUA; 2) e superdimensionaram o impacto da escolaridade e da zona de moradia, já que o grupo alvo de antipatia dos indivíduos menos escolarizados e de moradores de cidades pequenas, nos EUA, é a esquerda.

Para evitar o problema do viés derivado da escolha de determinados grupos como alvo da intolerância, esses autores formularam um modelo em que o pesquisador pergunta primeiro ao entrevistado qual o grupo que ele não gosta e, depois, faz perguntas específicas apenas sobre os direitos desses grupos. A lista de grupos englobava grupos extremistas de esquerda (como comunistas e socialistas) e de direita (facistas, membros da Ku Klux Klan, dentre outros), mas também grupos que não necessariamente se enquadram nessa divisão ideológica clássica, como militantes pró e contra o aborto, além de ateus. As perguntas formuladas após a identificação do grupo prioritário de desafeição envolviam o direito de se candidatar ao posto de presidente dos Estados Unidos, mas também liberdades menos relevantes, como ensinar em escolas públicas, passando pelos direitos de fazer discursos e participar de passeatas (Sullivan, Piereson e Marcus, 1982).

Essa forma de mensuração tem sido denominada de abordagem do least-liked group. Ao contrário dos estudos anteriores, essa medida de tolerância não tem como alvo um grupo predefinido, mas sim o grupo em relação ao qual o indivíduo se opõe.

Para além dessa discussão metodológica com implicações teóricas e empíricas sobre a amplitude e a intensidade da tolerância, a literatura tem avançado também de forma considerável na compreensão dos possíveis fatores que fazem com que alguns indivíduos sejam mais tolerantes do que outros. O trabalho de Sniderman (1975), por exemplo, aponta a autoestima e o aprendizado social como importantes preditores de posturas mais tolerantes. Sullivan, Piereson e Marcus (1982), por sua vez, destacam a percepção de ameaça, a baixa adesão a valores democráticos e a insegurança psicológica como fatores fortemente associados à intolerância. Mais recentemente Stenner (2005) inclui como condicionante relevante um traço de personalidade: o autoritarismo. 
Dentre todos esses fatores, a percepção de ameaça tem sido recorrentemente confirmada como preditor relevante. O estudo pioneiro de Stouffer (1955) já demonstrava que o nível de intolerância individual estava diretamente relacionado com a sensação (real ou imaginária) de ameaça oferecida por grupos impopulares a importantes valores ou à ordem constitucional como um todo.

Sullivan, Piereson e Marcus (1982), para medir o quanto os indivíduos se sentem ameaçados, apresentaram uma lista de pares de adjetivos contrastantes (fraco/forte, honesto/desonesto, confiável/não confiável, previsível/imprevisível, seguro/perigoso, importante/desimportante, violento/não violento, bom/mau) para que os entrevistados atribuíssem notas para o seu grupo de rejeição. Por meio de análise fatorial, essas notas foram combinadas em um indicador de ameaça para cada grupo least-liked que se revelou fortemente relacionado com a intolerância.

O apoio às normas democráticas tem sido apontado, desde a elaboração do modelo de Sullivan, Piereson e Marcus (1982), como outro importante condicionante da tolerância ${ }^{4}$. Embora a literatura tenha identificado o hiato existente entre, de um lado, o consenso normativo em torno dos procedimentos democráticos associados a majoritity rule and minority rights e, de outro, o apoio limitado na aplicação desses princípios abstratos a situações concretas envolvendo grupos extremistas, as evidências empíricas mostram, de forma enfática, que indivíduos com perfil mais liberal são também mais tolerantes em relação aos grupos de que não gostam.

Outro fator que tem sido recorrentemente apontado como preditor da tolerância é a insegurança psicológica. Associadas a determinadas condições sociais (como, por exemplo, o status social e a idade), características da personalidade individual, em especial o dogmatismo e a baixa autoestima, estimulam a intolerância política (Sullivan, Piereson e Marcus, 1982).

Além desses fatores, os preditores clássicos nos estudos sobre comportamentos e atitudes políticas têm também aparecido como relevantes nos estudos sobre tolerância política. Efeitos de escolaridade, religião, idade, ideologia e status social sobre a tolerância têm sido identificados desde o estudo pioneiro de Stouffer (1955).

Neste artigo, testamos, na opinião pública brasileira, alguns dos condicionantes apontados por essa tradição de estudos empíricos sobre a tolerância política. Esperamos, com isso, não apenas contribuir para o avanço dos estudos sobre a tolerância no Brasil, mas também para a compreensão dos processos e fenômenos políticos hoje em curso em nosso país.

\footnotetext{
4 Gibson, Duch e Tedin (1992) e também Finkel e Ernst (2005), seguindo essa pista, também confirmam a existência de relação entre medidas de apoio a instituições e processos democráticos e a tolerância política.
} 


\section{Dados e metodologia}

Para o contexto da América Latina, o Latin American Public Opinion Project (Lapop $)^{5}$ é a única fonte de dados sobre o tema e, até a sua onda de 2014, incluía em seu questionário apenas um grupo bastante genérico e ampliado de "pessoas que falam mal da forma de governo". Em relação a esse grupo, os entrevistados deveriam apontar seu grau de aprovação ao exercício de direitos políticos fundamentais por parte de seus membros: votar, manifestar-se publicamente, concorrer a cargos públicos e discursar.

Como já alertamos, esse procedimento abre uma janela considerável para erros de mensuração, principalmente porque aqueles que são críticos da atual forma de governo apresentam maior tendência a aprovar a concessão desses direitos. Devido ao viés de conteúdo, a tolerância de amplos segmentos da população não é medida, já que não se perguntou a respeito dos grupos que são alvo de sua antipatia. Para o caso brasileiro, felizmente a equipe do Lapop incluiu, em 2017, grupos alvos de intolerância com diversos perfis ideológicos.

Seguindo as orientações gerais propostas por Sullivan, Piereson e Marcus (1982), o questionário do Lapop apresenta a seguinte pergunta para identificação do grupo alvo de antipatia dos entrevistados:

Falando de alguns grupos de pessoas, poderia informar o quanto gosta ou desgosta dos listados abaixo. Usaremos agora uma escala de 1 a 10, na qual 1 significa "desgosto muito" e 10 significa "gosto muito".

a) Pessoas que defendem a legalização do aborto

b) Pessoas que defendem o regime militar

c) Comunistas

d) Petistas/Simpatizantes do PT

e) Peessedebistas/Simpatizantes do PSDB

Diferentemente da proposta de Sullivan, Piereson e Marcus (1982), o Lapop não formulou a questão direta sobre qual seria o grupo de maior rejeição dos entrevistados. 0 grupo-alvo foi, então, identificado mediante verificação daquele grupo com menor nota na escala de gosto. Nos casos em que o entrevistado atribuiu a menor pontuação a mais de um grupo, o empate foi resolvido por designação aleatória ${ }^{6}$.

\footnotetext{
5 Disponível em: <https://www.vanderbilt.edu/lapop/>. Acesso em: out. 2019. Agradecemos ao Latin American Public Opinion Project e seus principais apoiadores (Agência dos Estados Unidos para o Desenvolvimento Internacional, Banco Interamericano de Desenvolvimento e Universidade de Vanderbilt, por disponibilizarem os dados.

${ }^{6}$ A programação dos procedimentos de recodificação e análise está disponível em:<https://7d16063e-c0fe4a23-a94b-f082d525af3d.filesusr.com/ugd/b981c1_fa04a7f3dc6842bbab6337a06d206d3e.pdf >.
} 
Na sequência, os indivíduos são convidados a se posicionarem em relação à fruição de alguns direitos políticos do seu grupo de antipatia prioritário (o menos "gostado", em uma tradução literal do least liked). Para tanto, a seguinte questão é utilizada:

Falando do grupo de pessoas que o(a) sr./sra. menos gosta...

Em uma escala de 1 a 10, na qual 1 significa "desaprova fortemente" e 10 significa "aprova fortemente"...

a) O quanto o/a sr./sra. aprova o direito dessas pessoas de votar?

b) O quanto o/a sr./sra. aprova o direito dessas pessoas de fazer um discurso público?

c) O quanto o/a sr./sra. aprova o direito dessas pessoas de concorrer a um cargo público?

Tomadas de forma isolada, relativas a cada direito, ou na sua forma agregada, essas respostas serão analisadas de forma descritiva e também consideradas como variáveis dependentes em modelos multivariados construídos para identificar os condicionantes fundamentais das atitudes tolerantes no contexto nacional.

\section{A antipatia e a tolerância política no Brasil}

A Tabela 1 apresenta a distribuição dos grupos alvos de desafeição, levando em consideração aquele que recebeu a menor nota na escala de gosto pelos entrevistados:

Tabela 1

Grupos alvos de antipatia, Brasil, 2017 (\%)

\begin{tabular}{|l|c|}
\hline Pessoas que defendem o regime militar & 11 \\
\hline Peessedebistas/Simpatizantes do PSDB & 18,5 \\
\hline Petistas/Simpatizantes do PT & 18,8 \\
\hline Comunistas & 19,9 \\
\hline Pessoas que defendem a legalização do aborto & 31,8 \\
\hline
\end{tabular}

Fonte: Lapop, 2017.

Os "militaristas" são o grupo com menor ocorrência, com 11\% dos entrevistados os elegendo como o seu principal alvo de antipatia. Na sequência vêm os "peessedebistas", com $18,5 \%$, seguidos de perto pelos "petistas". Isso é compatível com pesquisas recentes sobre a redução dos níveis de partidarismo no contexto nacional (Ribeiro, Carreirão e Borba, 2016), mas surpreende ao mostrar que o PT está longe de deter o monopólio da desafeição popular em relação a partidos. Os comunistas ocupam a segunda posição, sendo apontados por 19,9\% da amostra nacional. O maior percentual de menções, com folga, recai sobre os defensores da legalização do aborto, com $31,8 \%$, o que revela um forte componente moral na escolha do grupo alvo de rejeição em nosso contexto. 
Uma vez identificados os grupos alvos de desafeição, a bateria seguinte de questões procura medir as atitudes dos entrevistados em relação à fruição de direitos políticos pelos membros de cada grupo. A escala aqui também é de 1 a 10 (1=desaprovo fortemente e 10 =aprovo fortemente).

A Tabela 2 apresenta, portanto, as médias de aprovação desses três direitos (votar, discursar e concorrer), o que torna possível identificarmos quais são os menos apoiados pelos entrevistados tendo como referência o grupo preferencial de antipatia:

Tabela 2

Médias de apoio a direitos para o grupo alvo de antipatia, Brasil, 2017

\begin{tabular}{|l|c|}
\hline Grupos & Média \\
\hline Votar & 6,6 \\
\hline Discursar em público & 6,1 \\
\hline Concorrer a cargo público & 5,8 \\
\hline
\end{tabular}

Fonte: Lapop, 2017.

Nota-se que o direito mais tolerado é o voto, seguido do direito de discursar em público e, por fim, vem o de concorrer a cargo público. Esse último direito, portanto, parece ser percebido como aquele que apresenta o maior potencial de ameaça quando exercido pelo grupo de maior rejeição pelo entrevistado. Infelizmente não temos parâmetros para avaliar comparativamente essas médias com outros momentos no tempo, já que a pesquisa do Lapop é a primeira do gênero realizada no Brasil.

Ainda que os grupos alvos de desafeição dos dois países sejam distintos, é possível levar em consideração os patamares de tolerância recentemente encontrados entre a população norte-americana para avaliarmos nossa situação. Gibson (2008), em interessante esforço de atualização do quadro da tolerância após meio século de pesquisas, aponta que, dentre os principais alvos de atitudes intolerantes, permanecem alguns grupos já destacados por Stouffer (1955), como comunistas e ateus, mas agora acompanhados pelos religiosos fundamentalistas, especialmente muçulmanos radicais. As atitudes de tolerância (liberdade de discursar em público e concorrer a cargos públicos) apresentam médias de 3,45 e 3,56 para uma escala de 5, na qual o 5 equivale ao maior grau de intolerância. Esse quadro é consideravelmente distinto do encontrado entre os brasileiros, que registraram médias de 6,1 e 5,8 (em uma escala de 0 a 10, no sentido inverso), respectivamente para esses dois direitos. É claro que essa comparação é limitada em razão dos principais grupos alvos de desafeição nos dois contextos, especialmente levando em consideração a história norte-americana recente, com seus episódios relacionados ao terrorismo. Ainda assim, com a falta de parâmetros mais adequados para a comparação, os dados sugerem que os brasileiros são mais tolerantes.

É importante também, nessa etapa descritiva da análise, identificarmos como se distribui essa média de tolerância para cada grupo alvo de antipatia (Tabela 3): 
Tabela 3

Médias de apoio a direitos por grupo alvo de antipatia, Brasil, 2017

\begin{tabular}{|l|c|c|c|}
\hline Grupos & Votar & Discursar & Concorrer \\
\hline Comunistas & 6,63 & 6,24 & $\mathbf{5 , 6 3}$ \\
\hline Pessoas que defendem a legalização do aborto & 6,58 & 6,24 & $\mathbf{5 , 8 4}$ \\
\hline Pessoas que defendem o regime militar & 7,35 & 6,85 & $\mathbf{6 , 3 8}$ \\
\hline Petistas/Simpatizantes do PT & $\mathbf{6 , 2 8}$ & $\mathbf{5 , 8 6}$ & $\mathbf{5 , 5 8}$ \\
\hline Peessedebistas/Simpatizantes do PSDB & 6,62 & 5,91 & $\mathbf{5 , 7 7}$ \\
\hline Teste de diferença de médias (p-valor)* & 0,019 & 0,016 & $\mathbf{0 , 1 5 9}$ \\
\hline
\end{tabular}

Fonte: Lapop, 2017.

*Diferenças são significativas quando o p-valor é igual ou menor que 0,05.

Confirmando os resultados anteriores, podemos perceber que as menores médias para todos os grupos ocorrem na última coluna, relativa ao direito de concorrer (em negrito). Entre os grupos, podemos perceber que petistas são os que registram as menores médias de aprovação de direitos nas três colunas. Entretanto, considerando os testes de diferenças de médias, constatamos que, quando o que está em jogo é a possibilidade de ocupar um cargo eletivo, a distinção entre os grupos não é estatisticamente significativa.

Também elaboramos uma versão qualitativa dessa medida de tolerância, que procura captar as posições extremas de tolerância/intolerância. Os entrevistados que se encontram nos pontos 1 e 2 das escalas de aprovação de direitos foram classificados como "extremamente intolerantes", aqueles localizados nos pontos 9 e 10 foram chamados de "extremamente tolerantes" e todos os demais são "moderados". A Tabela 4 apresenta a distribuição dessas categorias para cada um dos direitos:

Tabela 4

Tolerantes e intolerantes, por tipo de direito, Brasil, 2017 (\%)

\begin{tabular}{|l|c|c|c|}
\hline \multirow{2}{*}{ Direitos } & \multicolumn{3}{|c|}{ Tricotômica } \\
\cline { 2 - 4 } & Intolerantes & Moderados & Tolerantes \\
\hline Votar & 14,8 & 46,1 & 39,1 \\
\hline Discursar em público & 17,5 & 52,3 & 30,2 \\
\hline Concorrer a cargo público & 22,3 & 49,6 & 28,1 \\
\hline
\end{tabular}

Fonte: Lapop, 2017.

A distribuição indica percentuais maiores de tolerantes do que de intolerantes, apesar de a categoria mais frequente ser a dos moderados. Esse quadro é bastante diferente do encontrado por Gibson (2008), ainda que adotando procedimento de classificação distinto, pois, se comparado com o nosso, ele reduz o número de "moderados". Construindo uma classificação tricotômica pela junção dos valores 1 e 2 na categoria "tolerantes", 4 e 5 como "intolerantes" e deixando o ponto intermediário 3 como "incertos", esse autor encontra uma maioria de intolerantes entre todos os direitos 
avaliados. No caso do direito a concorrer, por exemplo, os intolerantes são $61,6 \%$, contra $29,5 \%$ de tolerantes.

Assim como anteriormente, também calculamos os percentuais de tolerantes, moderados e intolerantes por grupo prioritário de rejeição, com o objetivo de verificar se a distribuição se altera quando consideramos a divisão dos entrevistados no que diz respeito aos alvos da intolerância (Tabela 5):

Tabela 5

Tolerantes e intolerantes por grupo alvo de antipatia e direito, Brasil, 2017(\%)

\begin{tabular}{|l|c|c|c|c|c|c|c|c|c|}
\hline \multirow{2}{*}{ Direitos } & \multicolumn{3}{|c|}{ Tricotômica } & \multicolumn{3}{c|}{ Concorrer } \\
\cline { 2 - 11 } & \multicolumn{3}{|c|}{ Votar } & \multicolumn{3}{c|}{ Discursar } \\
\cline { 2 - 10 }$y$ & Int. & Mod. & Tol. & Int. & Mod. & Tol. & Int. & Mod. & Tol. \\
\hline $\begin{array}{l}\text { Pessoas que defendem o } \\
\text { regime militar }\end{array}$ & 15,3 & 41,4 & 43,3 & 15,8 & 47,5 & 36,7 & 19,6 & 50 & 30,4 \\
\hline Petistas/Simpatizantes do PT & 14,2 & 52 & 33,7 & 16,3 & 58,7 & 24,9 & 26,7 & 51,8 & 21,5 \\
\hline Comunistas & 16 & 43,9 & 40,1 & 21,6 & 46,7 & 31,7 & 24,7 & 44,6 & 30,7 \\
\hline $\begin{array}{l}\text { Peessedebistas/Simpatizantes } \\
\text { do PSDB }\end{array}$ & 19,3 & 41,7 & 39 & 19,5 & 51,9 & 28,6 & 26,3 & 42,8 & 30,8 \\
\hline $\begin{array}{l}\text { Pessoas que defendem a } \\
\text { legalização do aborto }\end{array}$ & 11 & 48,7 & 40,3 & 13 & 56,3 & 30,7 & 16 & 56 & 28 \\
\hline
\end{tabular}

Fonte: Lapop, 2017.

No primeiro grupo temos aqueles que apontam os "militaristas" como o que menos gostam. Os percentuais de tolerantes são mais elevados nos dois primeiros direitos, na comparação com os demais grupos de entrevistados. Isso indica que a maioria daqueles que elegem esse grupo como o alvo da sua antipatia os toleram politicamente. Esse quadro já era esperado, já que os maiores opositores aos militaristas são democratas, que aderem mais aos princípios liberais que freiam a intolerância política (Marcus et al., 1995).

O segundo grupo, que tem como alvo de desafeição os petistas ou simpatizantes do PT, apresenta percentuais de tolerantes consideravelmente menores do que os militaristas, com diferença média de mais de 9 pontos percentuais se considerarmos os três direitos. Situação semelhante é verificada no grupo que toma como alvo os peessedebistas ou simpatizantes do PSDB, que, apesar de apresentar percentuais de tolerantes maiores do que o grupo desafeto aos petistas nos três direitos, também está aquém dos números registrados no grupo relativo aos militaristas no direito a votar e discursar.

Os entrevistados que apontam os comunistas como o seu grupo de maior antipatia, por sua vez, apresentam contingentes de tolerantes próximos das médias calculadas considerando os cinco grupos, respectivamente 39,3\%, 30,5\% e 28,3\% para cada direito. Essa tendência se repete no grupo de desafetos das pessoas que defendem a legalização do aborto com percentuais muito próximos dessas médias. 
Especificamente no caso dos comunistas, a comparação com o caso norteamericano é possível usando resultados apresentados por Gibson (2008) sobre uma pergunta que mede a disposição dos entrevistados de proibir manifestações. Nos EUA, $53,6 \%$ da amostra declarou apoio à proibição de manifestações públicas de comunistas, contra $41 \%$ de contrários. No Brasil, apesar de não haver pergunta específica sobre o direito à manifestação, o percentual de tolerantes é sempre maior em relação a esse grupo alvo de desafeição.

O próximo passo da nossa análise sobre os condicionantes da tolerância é construir uma medida integrada, incluindo as atitudes de aprovação ou reprovação dos três direitos. Para tanto conduzimos o teste de consistência interna proposto por Cronbach $(1951)^{7}$ e o valor encontrado de 0,85 confirmou a validade dessa redução. Como as distribuições percentuais anteriormente exibidas já indicavam, existe uma forte tendência de respostas semelhantes às questões sobre os três direitos. Com isso, procedemos ao cálculo de um índice somatório que denominamos Índice de Tolerância Política (ITP) ${ }^{8}$, que, após a padronização para variar entre $0-10$, registrou a média de 6,19 . Novamente essa média é bastante distinta da encontrada por Gibson (2008), que, em uma escala de 5 pontos organizada na direção inversa, encontrou média de 3,52.

Assim como procedemos em relação às medidas isoladas, também tricotomizamos essa medida usando os extremos da escala9 ${ }^{9}$. As distribuições são exibidas na Tabela 6:

Tabela 6

Tolerantes e intolerantes, Brasil, 2017(\%)

\begin{tabular}{|c|l|c|c|c|c|c|c|}
\hline \multicolumn{2}{|c|}{} & Geral & Militar & Comunistas & Aborto & Petistas & Peessedebistas \\
\hline \multirow{3}{*}{ Tricotômica } & Intolerante & 10,3 & 12,9 & 11,5 & 6,8 & 11,2 & 12,9 \\
\cline { 2 - 8 } & Moderado & 60,2 & 56,1 & 59,2 & 63,9 & 65,2 & 56,1 \\
\cline { 2 - 8 } & Tolerante & 29,4 & 31 & 29,7 & 29,2 & 23,6 & 31 \\
\hline
\end{tabular}

Fonte: Lapop, 2017.

Pode-se perceber que: 1) a grande maioria dos brasileiros é moderada; 2) quase um terço da população manifesta atitudes consistentemente tolerantes; 3) uma minoria revela atitudes radicalmente intolerantes. A Tabela 6 mostra, mais uma vez, o Brasil mais

\footnotetext{
7 O coeficiente alfa de Cronbach (a) foi proposto por Lee Cronbach em artigo publicado em 1951, como um procedimento de estimação da confiabilidade de instrumentos aplicados em pesquisas de survey. Basicamente mede a correlação entre respostas em um questionário, sendo calculado a partir da variância dos itens individuais e da variância da soma dos itens.

8 Para a construção desse índice foram somadas as pontuações das escalas das três variáveis originais para cada entrevistado. A variável "resultado dessa soma" foi padronizada posteriormente para apresentar amplitude de 0 a 10 pelo procedimento de divisão dos valores pelo valor máximo verificado, multiplicado por 10.

9 Para construir essa variável com três categorias, foram juntados os casos com pontuações de 0 a 1 na condição "intolerante", aqueles que pontuaram de 8 a 10 foram classificados como "tolerantes" e todos os demais como "moderados" (pontuações de 3 a 7).
} 
tolerante do que os EUA retratado por Sullivan, Piereson e Marcus (1982) e, mais recentemente, por Gibson (2008).

Como já sugerimos anteriormente, possivelmente isso está associado ao fato de que vivemos num ambiente com menos mobilização e tensão em relação a grupos radicais do que os EUA. Isso mostra a importância do contexto para explicar diferenças entre países. Os contextos variam em função das clivagens sociais, da ameaça real representada pelo grupo alvo da intolerância, das normas e práticas jurídicas e da cultura política (Sullivan et al., 1985).

A distribuição da intolerância por grupos, no Brasil, segue o padrão ainda mais difuso do que Sullivan, Piereson e Marcus (1982) encontraram nos EUA, com dois grupos sendo alvos de intolerância de mais de $20 \%$ dos estadunidenses (comunistas, com 29\%, e Ku Klux Klan, com 24\%).

\section{Bases sociais e atitudinais da escolha do grupo alvo de antipatia}

Nesta seção, estabelecemos um diálogo com a literatura norte-americana que analisa as bases sociais (ou demográficas) e atitudinais da escolha de um grupo como o alvo preferencial de antipatia e da manifestação de atitudes intolerantes em relação a esse grupo, com especial atenção ao modelo-síntese de Sullivan, Piereson e Marcus (1982). Mantemos, assim, a proposta do presente artigo de explorar, comparativamente, 0 rendimento do estudo sobre tolerância política no Brasil a partir de medidas compatíveis com aquelas utilizadas na literatura internacional.

Apesar da oportunidade inédita de testar vários desses fatores, alguns condicionantes importantes identificados na literatura não constam do survey do Lapop 2017. Esse é o caso da influência da percepção de ameaça (real ou imaginária) sobre os níveis de rejeição e tolerância política dos brasileiros. Não há informações complementares sobre a avaliação que os entrevistados fazem dos seus respectivos grupos alvos de rejeição, tal como metodologia proposta por Sullivan, Piereson e Marcus (1982).

Um segundo conjunto de preditores recorrentes na literatura se relaciona à adesão a normas democráticas, tais como a liberdade de expressão e os direitos das minorias (Sullivan, Piereson e Marcus, 1982; Gibson, Duch e Tedin, 1992; Finkel e Ernst, 2005). Para testar essa dimensão, selecionamos uma medida de apoio à participação (Verba, Schlozman e Brady, 1995) ${ }^{10}$.

Desde o estudo clássico de Stouffer (1955), a religiosidade tem sido considerada um fator importante na explicação da tolerância política. Em sua obra, o autor aponta que, apesar de a denominação importar, o que melhor explica a intolerância é a frequência aos cultos e celebrações. Nunn, Crockett e Williams (1978), três décadas depois, confirmam

\footnotetext{
10 A pergunta, no Lapop, é: "A participação de pessoas em manifestações permitidas por lei. Até que ponto aprova ou desaprova?". Os entrevistados eram levados a escolher em uma escala de 1 a 10, qual o ponto que melhor representa sua posição sobre o assunto.
} 
esse achado e afirmam que as diferenças nos níveis de tolerância entre religiosos não praticantes e os mais ativos foi ampliada. Adaptando o modelo analítico de Stouffer aos dados do General Social Survey (GSS) de 2008, Eisenstein e Clark (2015) chegam a resultados semelhantes, reafirmando a importância do envolvimento religioso na explicação de atitudes intolerantes.

Seguindo esses estudos, utilizamos em nossos modelos um índice de ativismo religioso composto por uma medida comportamental e outra atitudinal. A primeira é derivada de uma pergunta sobre a frequência dos entrevistados a missas e cultos e a segunda é obtida pela importância da religião na vida do entrevistado.

Outra medida presente nos estudos sobre tolerância é o interesse por política, considerado um dos principais preditores em estudos sobre o comportamento político, seja na explicação da sofisticação política (Converse, 1964; Neuman, 1986; Luskin, 1990; Delli Carpini e Keeter, 1996), da participação política (Verba, Schlozman e Brady, 1995) ou de atitudes democráticas (Moisés, 2008; Booth e Seligson, 2009; Salinas e Booth, 2011; Booth e Richard, 2015; Fuks, Casalecchi e Araújo, 2017; Norris, 1999, 2011; Dalton, 1999, 2004; Klingemann, 1999). O seu efeito é sempre positivo, no sentido de formar cidadãos politicamente competentes. O indivíduo que tem mais interesse por política não apenas tem mais informação política e participa mais, mas também tem mais contato com as normas e práticas democráticas. Esperamos, portanto, que o interesse por política tenha um efeito positivo sobre a tolerância política.

A partir da proposição clássica de que a educação formal permite a compreensão e internalização de normas de tolerância (Lipset, 1959, p. 55-56), incluímos em nosso modelo a escolaridade. As pesquisas na área reiteram constantemente que, assim como o interesse político, quanto maior a escolaridade maior a adesão à democracia e a seus princípios. Esses resultados são consistentes tanto nas novas democracias (Evans e Rose, 2007; Moisés e Carneiro, 2008; Booth e Seligson, 2009) como nas mais antigas (Dalton, 1999, 2004). Além disso, alguns estudos seminais mostram que a escolaridade também afeta a participação (Verba, Schlozman e Brady, 1995) e a própria tolerância (Delli Carpini e Keeter, 1996; Nie, Junn e Stehlik-Barry, 1996). Estudos específicos sobre tolerância também destacam o papel importante da escolaridade na formação de atitudes tolerantes, especialmente mediante o seu efeito positivo sobre a segurança psicológica e a adesão às normas democráticas (Sullivan, Piereson e Marcus, 1982).

Embora a literatura sobre tolerância política considere a ideologia como indicador de atitudes conservadoras ou liberais em relação a direitos de minorias, utilizamos, em nosso modelo, a ideologia para testar o efeito da intensidade desse posicionamento, como traço do perfil psicológico do indivíduo, sobre a tolerância. Nossa expectativa é de que a estrutura do sistema de crenças do indivíduo que adota posições extremistas no espectro ideológico seja semelhante, em termos de intensidade e consistência interna, à de indivíduos com traços de personalidade dogmática (Sullivan, Piereson e Marcus, 1982), portanto, sendo menos flexíveis em relação a ideias/grupos a que se opõem. Sendo assim, 
a variável ideologia foi elaborada, aqui, de forma diferente da que está nos modelos de antipatia e tolerância, sendo que, nesse último modelo, a codificação confere destaque às posições intensas à esquerda e à direita.

Consideramos também a idade, presente na literatura sobre tolerância desde a pesquisa de Stouffer (1955). Nesse estudo inaugural, foram identificadas importantes diferenças nos níveis de tolerância a comunistas, ateus e socialistas entre as distintas coortes etárias, sendo os mais jovens mais tolerantes. Fazendo uma importante distinção entre idade e geração, Cutler e Kaufman (1975) confirmam os achados anteriores de que, com o avançar da idade, os indivíduos tendem a se tornar menos tolerantes, mas identificam também diferenças geracionais relevantes. Ou seja, quando comparam jovens e velhos da década de 1950 com essas mesmas coortes de 1970, verificam que as gerações mais recentes tendem a manifestar atitudes mais tolerantes. Resultados semelhantes são encontrados por Davis (1975), Nunn, Crockett e Williams (1978) e Sullivan, Piereson e Marcus (1982). Infelizmente não dispomos de dados longitudinais para empreender uma análise geracional tal como fazem esses estudos.

Nos modelos que investigam as bases da rejeição, optamos pela análise do ciclo de vida. Já para a análise dos condicionantes da tolerância, tratamos a "idade" como variável indicadora de geração política, portanto distinta do que fizeram os estudos listados acima. Tomando como elemento definidor a socialização política ocorrida durante a vigência do regime militar, findo em 1985, ou dentro de um ambiente configurado por instituições democráticas, distinguimos a amostra em dois grupos geracionais. Incluímos, assim, considerações de natureza contextual, pois, nas jovens democracias latinoamericanas, a socialização política das gerações apresenta uma clivagem fundamental: ter vivido apenas no regime democrático ou ter passado também pela experiência autoritária (Moreno e Lagos, 2016).

Um estudo recente sobre a América Latina (Fuks, Paulino e Casalecchi, 2018) aponta que as gerações que viveram os dois regimes apoiam mais a democracia do que aqueles que só foram socializados na democracia. Segundo a interpretação dos autores, as gerações mais velhas manifestam maior adesão à democracia por terem experimentado a privação de direitos civis e políticos. Nossa hipótese é de que, embora valorizem mais o regime democrático que tiveram de conquistar, as gerações mais velhas apoiam menos do que as mais novas os princípios liberais da democracia, especialmente o direito das minorias. Esses valores, assim como o elenco de valores de autoexpressão (Inglehart e Welzel, 2005), estão mais associados a processos por meio dos quais a sociedade tornase mais liberal do que às ameaças que operam no nível da repressão estatal.

Para a construção dessa variável, estabelecemos a idade de 15 anos como marco definidor das gerações, considerando quem tinha 15 anos ou mais no ano que se iniciou a transição como socializado no regime anterior (autoritário) e quem tinha 14 ou menos como socializado apenas no regime democrático. Como os dados provêm de pesquisa conduzida em 2017, aqueles com mais de 47 anos pertencem à geração que teve 
experiência política em mais de um regime político e aqueles com 47 anos ou menos pertencem à geração que foi socializada e teve experiência política apenas na democracia.

Quadro 1

Informações sobre as variáveis independentes

\begin{tabular}{|l|c|}
\hline Variável & $\begin{array}{c}\text { Codificação } \\
\text { Apoio à participação }\end{array}$ \\
\hline Frequência a cultos religiosos 10 (1 a 10)
\end{tabular}

Fonte: Lapop, 2014.

Começamos a análise dos resultados pelos condicionantes da rejeição. Optamos por recodificar a variável que identifica o grupo preferencial de antipatia em cinco medidas dicotômicas. Assim, em cada uma delas a codificação é 0 ou 1 , sendo que 0 indica que 0 entrevistado não aponta o grupo $X$ como o seu desafeto preferencial, enquanto 01 indica que o grupo é o alvo de sua rejeição. Na Tabela 7 são exibidos os resultados desses modelos:

Tabela 7

Condicionantes da escolha do grupo alvo de antipatia, Brasil, 2017

\begin{tabular}{|c|c|c|c|c|c|c|}
\hline & & \multicolumn{5}{|c|}{$\begin{array}{l}\operatorname{Exp}(B) \\
\text { (Erro) }\end{array}$} \\
\hline & & Aborto & Militar & Comunistas & Petistas & Peessedebistas \\
\hline \multicolumn{2}{|c|}{$\begin{array}{l}\text { Adesão ao princípio da } \\
\text { participação }\end{array}$} & $\begin{array}{l}1,00 \\
(, 024)\end{array}$ & $\begin{array}{c}0,95 \\
(, 039)\end{array}$ & $\begin{array}{c}1,0 \\
(, 028)\end{array}$ & $\begin{array}{c}0,99 \\
(, 029)\end{array}$ & $\begin{array}{c}1,03 \\
(, 029)\end{array}$ \\
\hline \multirow{3}{*}{ Ideologia } & Esquerda & Ref. & Ref. & Ref. & Ref. & Ref. \\
\hline & Centro & $\begin{array}{c}0,78 \\
(, 169)\end{array}$ & $\begin{array}{c}0,94 \\
(, 255)\end{array}$ & $\begin{array}{c}1,37 \\
(, 194) \\
\end{array}$ & $\begin{array}{c}1,35 \\
(, 193)\end{array}$ & $\begin{array}{c}0,78 \\
(, 198)\end{array}$ \\
\hline & Direita & $\begin{array}{c}1,04 \\
(, 165)\end{array}$ & $\begin{array}{c}0,79 \\
(, 268)\end{array}$ & $\begin{array}{c}1,35 \\
(, 190)\end{array}$ & $\begin{array}{c}0,98 \\
(, 206)\end{array}$ & $\begin{array}{c}0,81 \\
(, 196)\end{array}$ \\
\hline \multicolumn{2}{|c|}{ Religiosidade } & $\begin{array}{c}1,13 * * * \\
(, 034)\end{array}$ & $\begin{array}{l}0,90 * \\
(, 052)\end{array}$ & $\begin{array}{c}0,94 \\
(, 039)\end{array}$ & $\begin{array}{c}1,01 \\
(, 040)\end{array}$ & $\begin{array}{c}0,94 \\
(, 039)\end{array}$ \\
\hline \multicolumn{2}{|c|}{ Interesse por política } & $0,87 \#$ & $1,46 * * *$ & 1,09 & $0,82 *$ & 1,03 \\
\hline
\end{tabular}


EDNALDO RIBEIRO; MARIO FUKS

\begin{tabular}{|c|c|c|c|c|c|c|}
\hline & & \multicolumn{5}{|c|}{$\begin{array}{c}\operatorname{Exp}(B) \\
\text { (Erro) }\end{array}$} \\
\hline & & Aborto & Militar & Comunistas & Petistas & Peessedebistas \\
\hline & & $(, 078)$ & $(, 113)$ & $(, 087)$ & $(, 097)$ & $(, 090)$ \\
\hline \multirow{3}{*}{ Escolaridade } & Fundamental & Ref. & Ref. & Ref. & Ref. & Ref. \\
\hline & Médio & $\begin{array}{c}1,18 \\
(, 157)\end{array}$ & $\begin{array}{c}0,82 \\
(, 263)\end{array}$ & $\begin{array}{c}0,94 \\
(, 181)\end{array}$ & $\begin{array}{c}1,10 \\
(, 184)\end{array}$ & $\begin{array}{c}0,89 \\
(, 198)\end{array}$ \\
\hline & Superior & $\begin{array}{c}1,05 \\
(, 254)\end{array}$ & $\begin{array}{l}2,57 * * \\
(, 323) \\
\end{array}$ & $\begin{array}{c}0,84 \\
(, 284)\end{array}$ & $\begin{array}{c}0,71 \\
(, 329)\end{array}$ & $\begin{array}{c}0,63 \\
(, 313)\end{array}$ \\
\hline \multirow{3}{*}{ Faixa etária } & Até 30 anos & Ref. & Ref. & Ref. & Ref. & Ref. \\
\hline & 31 a 50 anos & $\begin{array}{c}0,69 * \\
(, 153) \\
\end{array}$ & $\begin{array}{l}0,63 \# \\
(, 239) \\
\end{array}$ & $\begin{array}{l}1,77^{* *} \\
(, 194) \\
\end{array}$ & $\begin{array}{c}1,34 \\
(, 182) \\
\end{array}$ & $\begin{array}{c}0,98 \\
(, 183) \\
\end{array}$ \\
\hline & $\begin{array}{l}+ \text { de } 50 \\
\text { anos }\end{array}$ & $\begin{array}{c}0,52 * * \\
(, 207) \\
\end{array}$ & $\begin{array}{l}0,54 * \\
(, 323) \\
\end{array}$ & $\begin{array}{c}, 22 * * * \\
(, 225) \\
\end{array}$ & $\begin{array}{c}0,76 \\
(, 261) \\
\end{array}$ & $\begin{array}{c}1,15 \\
(, 231) \\
\end{array}$ \\
\hline \multicolumn{2}{|l|}{ Sexo } & $\begin{array}{c}1,18 \\
(, 141)\end{array}$ & $\begin{array}{c}0,81 \\
(, 225)\end{array}$ & $\begin{array}{c}0,86 \\
(, 164)\end{array}$ & $\begin{array}{c}0,98 \\
(, 168)\end{array}$ & $\begin{array}{c}1,09 \\
(, 166)\end{array}$ \\
\hline \multicolumn{2}{|l|}{$\mathrm{N}$} & 1029 & 1029 & 1029 & 1029 & 1029 \\
\hline \multicolumn{2}{|l|}{ AIC } & 1275,7 & 647,89 & 1031,6 & 982,26 & 1010,4 \\
\hline
\end{tabular}

Fonte: Lapop, 2017.

Níveis de significância: $* * * \leq, 000 ; * * \leq, 001 ; * \leq, 05 ; \# \leq, 1$.

O primeiro modelo, portanto, estima os efeitos das variáveis sobre a probabilidade de o entrevistado escolher como seu objeto de rejeição o grupo de pessoas que defendem a legalização do aborto. Considerando o nível de significância usual nas ciências sociais, apenas a religiosidade e a faixa etária se mostraram relevantes. O efeito da religião caminha na direção esperada, elevando a probabilidade de seleção do grupo em questão em $13 \%$ a cada ponto da escala que vai de 0 a 7 . Ou seja, quanto mais ativo religiosamente o indivíduo é, maior é a probabilidade de ele selecionar esse grupo como seu alvo preferencial de rejeição.

Os coeficientes para as faixas etárias, por sua vez, indicam que os mais jovens tendem a escolher esse grupo com mais frequência do que os mais velhos. É importante observar que os membros do grupo com idade entre 31 e 50 anos em 2017 (ano da coleta) apresentam $31 \%$ menos chance de selecionar esse grupo do que o grupo de referência (até 30 anos). A diferença é ainda maior na comparação com os mais velhos (acima de 50 anos), já que estes apresentam probabilidade de escolha $48 \%$ menor. O interesse por política é também relevante nesse primeiro modelo, com cada avanço na escala de quatro pontos reduzindo a probabilidade de seleção do grupo em $13 \%$.

Passando ao grupo composto por pessoas que defendem o regime militar, novamente a religiosidade se mostra relevante, mas dessa vez reduzindo a probabilidade de seleção. Cada ponto na escala (que vai de 0 a 7) reduz essa chance em $10 \%$. O interesse por política eleva essa probabilidade em 46\%, o que é bastante expressivo se considerarmos que esse preditor está codificado em uma escala de quatro pontos. Efeito igualmente expressivo é encontrado na escolaridade, já que os entrevistados com formação superior apresentam $157 \%$ mais chance do que os entrevistados com ensino 
fundamental de selecionarem os chamados militaristas como seus desafetos principais. Quanto às faixas etárias, identificamos que os dois grupos mais velhos apresentam menores chances de selecionar os militaristas, tendo como referência para comparação os entrevistados mais jovens (até 30 anos). Ainda que o nível de significância do coeficiente ultrapasse 0,10, a direção do efeito da ideologia vai no sentido esperado, pois o autoposicionamento ideológico à esquerda eleva em $21 \%$ a chance de seleção desse grupo, comparando com o grupo de referência dos que se identificam com a direita.

Em relação aos comunistas, apenas a idade se mostrou preditor relevante. Os mais velhos, nesse caso, apresentam probabilidade consideravelmente maior de seleção desse grupo político como alvo de desafeição. Para o grupo intermediário (de 31 a 50 anos), essa diferença é de $77 \%$, e para o grupo mais velho chega a impressionantes $222 \%$. Novamente, mesmo não passando no teste de hipótese, os posicionamentos ideológicos de centro e de direita produzem, respectivamente, acréscimos de 37 e 35 pontos percentuais nessa probabilidade.

Considerando o grupo dos petistas ou simpatizantes do PT, a única variável estatisticamente significativa é o interesse por política, com efeito redutor de $18 \%$ a cada ponto na escala. Ampliando o limite da análise, podemos verificar que a identificação ideológica com o centro eleva essa chance em 35\%. Já quando o alvo da desafeição é o grupo de peessedebistas ou simpatizantes do PSDB, nenhuma das variáveis atinge o nível de significância usual. Os efeitos do posicionamento ideológico de centro e de direita, apesar de não significativos para o teste de hipótese, são negativos, reduzindo em 22 e 19 pontos percentuais a probabilidade de seleção, respectivamente. Os efeitos redutores da escolaridade também merecem ser registrados, já que os que possuem o ensino médio têm $11 \%$ menos chance de seleção desse grupo partidário e aqueles com formação superior têm redução de $37 \%$.

Esses resultados apresentam um certo padrão. Primeiro, a idade é o principal preditor da escolha do grupo de rejeição. Quanto mais velho o indivíduo, mais ele escolhe grupos tradicionais de esquerda, como os comunistas, e menos os de direita, como os que apoiam o regime militar. Os mais jovens são politicamente mais progressistas, mas, surpreendentemente, moralmente mais conservadores na escolha do seu grupo preferencial de antipatia. São eles que têm mais chances de rejeitar as pessoas que defendem a legalização do aborto.

A religiosidade e o interesse por política explicam, em grande medida, preferências conservadoras, tanto morais como políticas, mas em sentidos opostos. Enquanto a religiosidade é um fator decisivo na escolha das pessoas que defendem a legalização do aborto como seu principal grupo rejeitado, o interesse por política opera no sentido de diminuir as chances dessa escolha. O padrão oposto pode ser observado em relação aos que apoiam o regime militar, com a religiosidade diminuindo a probabilidade da desafeição e o interesse por política aumentando. Embora o ensino superior também explique a maior probabilidade de rejeição dos que apoiam o regime militar, merece destaque o fato de que, 
de maneira geral, o interesse por política seja muito mais relevante do que a escolaridade para explicar a escolha do grupo principal de antipatia dos brasileiros, com o maior interesse por política apresentando um viés contra os grupos de direita. O maior interesse por política também diminui a propensão da escolha dos petistas como grupo least liked.

Chama a atenção também o fato de que as variáveis, no nosso modelo, explicam muito pouco a escolha dos dois principais partidos brasileiros como principal alvo de rejeição. Os dados apresentados na Tabela 1 já mostravam que 37\% dos brasileiros nutrem profunda rejeição por esses dois partidos. Os modelos de regressão nos trazem uma nova informação: essa rejeição aos dois partidos é dispersa na sociedade, incluindo igualmente indivíduos de alta e baixa escolaridade, seculares e religiosos, jovens e velhos, mulheres e homens e, mais surpreendente ainda, esquerdistas e direitistas. Parece, então, que o que hoje percebemos como polarização política, no nível da elite política, começa a assumir, na opinião pública, a forma de antipartidarismo. Mas essa é uma questão para outro estudo.

O mais importante aqui é que as bases sociais e atitudinais da escolha do principal grupo de antipatia não são aleatórias e a religiosidade, a idade e o interesse por política interferem nessa escolha. Isso valida o desenho da metodologia que utilizamos, permitindo captar a diversidade dos grupos que podem vir a ser objetos de intolerância de diferentes segmentos da população brasileira.

\section{Os condicionantes da tolerância política}

Para a análise das bases sociais e atitudinais da tolerância política, assim como fizemos na parte descritiva da análise, utilizamos tanto o índice de tolerância política como uma versão categórica da variável, que a distingue em três grupos: intolerantes, moderados e tolerantes. Usando a primeira variável como dependente, estimamos um modelo linear; e, usando a segunda, um modelo logístico multinomial. Os resultados são apresentados na Tabela 8: 
Tabela 8

Condicionantes da tolerância política, Brasil, 2017

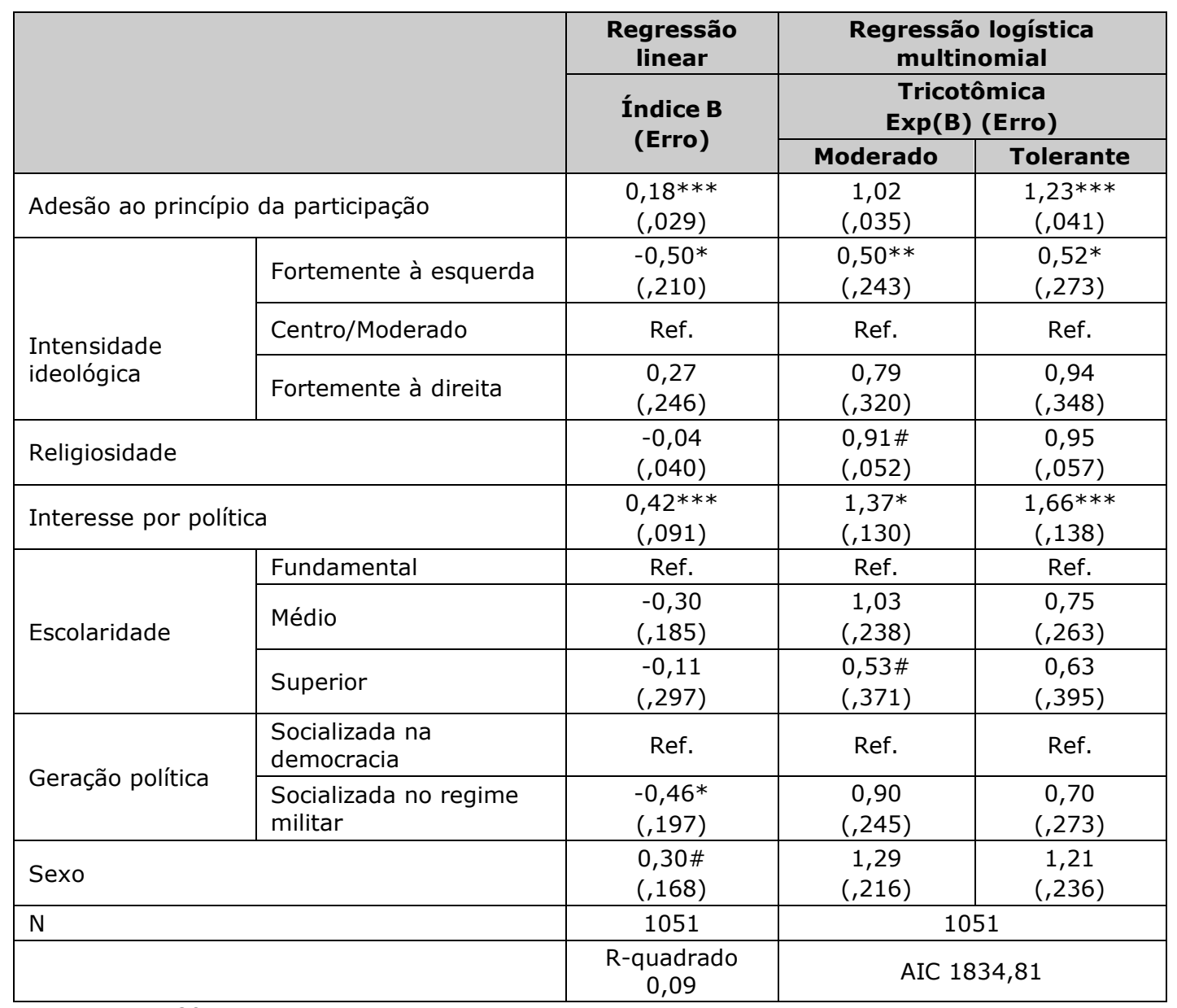

Fonte: Lapop, 2017.

Níveis de significância: $* * * \leq, 000 ; * * \leq, 001 ; * \leq, 05 ; \# \leq, 1$.

O primeiro modelo mostra efeito estatisticamente significativo para a adesão ao princípio da participação política, com elevação de 0,18 ponto a cada avanço na escala que varia de 1 a 10. Quanto à ideologia, considerando os posicionamentos fortemente à esquerda ou direita, apenas a categoria que representa o primeiro grupo apresenta efeito significativo, reduzindo em meio ponto o ITP, na comparação com os indivíduos de centro. O interesse por política, por sua vez, apresentou efeito positivo, elevando em 0,42 a medida de tolerância a cada avanço em sua escala de quatro pontos. Outra variável com efeito estatisticamente significativo foi a geração política, indicando que os indivíduos socializados no regime militar têm pontuação 0,46 menor do que aqueles que só experimentaram instituições democráticas. Além disso, ser mulher eleva em 0,30 ponto o índice. 
Podemos sintetizar então afirmando que a tolerância tende a ser maior entre os que aderem com maior intensidade à norma da participação política, os que são de centro (quando comparados com a esquerda), os interessados por política e os socializados na democracia.

O modelo logístico multinomial acompanha, em grande medida, esses resultados. Assim, quanto maior a adesão ao princípio da participação, maior é a probabilidade de estar entre os tolerantes. Consistentemente, o posicionamento mais fortemente posicionado à esquerda reduz a chance de estar entre os moderados e tolerantes (50\% e $48 \%$, respectivamente). O interesse por política afeta, mais uma vez, de forma positiva a probabilidade de ser moderado ou tolerante, em 37 e 66 pontos percentuais, respectivamente. Além disso, a religiosidade afeta negativamente em $9 \%$ a probabilidade de estar entre os moderados, enquanto a formação superior apresenta efeito redutor de $47 \%$ sobre a chance de estar nesse grupo moderado.

De forma geral, os resultados desses dois modelos sobre intolerância e o do modelo dos grupos de antipatia se aproximam. O interesse por política (e não a escolaridade) se revela aqui como o "solvente universal" (Converse, 1972) na explicação da tolerância política no Brasil. Ele não só é um forte preditor da escolha dos grupos de desafeição como também explica o maior ou menor grau de tolerância a esses grupos. De tal forma, que se pudéssemos sugerir um caminho para aumentar a tolerância no Brasil, ela seria baseada no aumento do interesse por política. Supreendentemente, a escolaridade não apenas não contribui para ganhos adicionais de tolerância, mas, quando importa, ela promove a intolerância. É um desafio explicar essa singularidade do efeito da escolaridade no Brasil, especialmente considerando que um dos poucos consensos da literatura sobre cultura política é que a escolaridade é um catalizador de atitudes democráticas e tolerantes. Isso merece ser explorado em estudo específico, para o qual sugerimos a seguinte questão de pesquisa: seria isso um indício da particularidade das atitudes das elites em sociedades desiguais?

Outro fator que se destaca tanto na escolha do grupo de antipatia como na tolerância política é a idade, revelando a força dos efeitos geracionais e/ou do ciclo de vida. A interpretação, nesse caso, é mais complexa do que a do interesse por política, pois não segue um único padrão.

Os mais jovens são socializados num ambiente, local e global, que estimula atitudes e comportamentos mais liberais. Isso explica por que os mais jovens, comparados com as gerações mais velhas, têm maiores chances de ser tolerantes e são menos propensos a escolher os comunistas como seu grupo de desafeição. Mas, certamente, fica de fora dessa linha de interpretação a sua maior probabilidade de ter os defensores do aborto como seu alvo preferencial de rejeição. Assim como no caso da escolaridade, seria necessário um estudo específico sobre gerações e tolerância política para analisar esse resultado de forma mais cuidadosa.

Como a nossa medida de intolerância foi elaborada com base na pesquisa de 
Sullivan, Piereson e Marcus (1982), cabe concluir nossa análise sistematizando a comparação entre os seus principais resultados e os que apresentamos neste artigo. Obviamente, essa comparação tem limitações pelo fato de não dispormos de uma medida de percepção de ameaça e a segurança psicológica reduziu-se, em nosso estudo, a apenas uma de suas dimensões, o dogmatismo. Esses dois fatores, além do apoio às normas democráticas, são os únicos que, no estudo de Sullivan, Piereson e Marcus (1982), apresentaram efeitos diretos sobre a tolerância.

Nosso artigo confirma o efeito do dogmatismo, medido em termos de intensidade do autoposicionamento ideológico. A evidência nesse sentido é a maior probabilidade de os "centristas" serem mais tolerantes (Lipset, 1959). No entanto, essa relação entre centro e polos não é simétrica, pois o efeito de se situar no centro apresentou significância estatística apenas na comparação com o posicionamento fortemente à esquerda. De forma mais categórica e inequívoca, nossos modelos também confirmam o resultado dos estudos de Sullivan, Piereson e Marcus (1982) no que se refere aos efeitos positivos da adesão a normas democráticas sobre a tolerância política.

Por outro lado, fatores que apresentaram apenas efeitos indiretos e moderados ou mesmo nenhum efeito na investigação de Sullivan, Piereson e Marcus tiveram destaque em nossos modelos. Esse é o caso do interesse por política, da idade e da religião, como evidenciado pela análise realizada.

\section{Considerações finais}

Neste artigo procuramos trazer o debate internacional sobre a tolerância política para o campo dos estudos sobre comportamento político no Brasil. Com isso, buscamos contribuir para minimizar a lacuna existente nos estudos sobre cultura política democrática no Brasil, incluindo um de seus princípios e valores mais substantivos. Isso só se tornou possível a partir dos dados disponibilizados pelo Barômetro das Américas de 2017, que incluiu grupos alvos de intolerância com diversos perfis ideológicos, superando assim os problemas derivados do viés de conteúdo das análises baseadas em grupos com perfis ideológicos homogêneos.

Assim, testamos, na opinião pública brasileira, alguns dos condicionantes apontados por essa tradição de estudos empíricos sobre a tolerância política. Entre os resultados mais importantes, apontamos a natureza não aleatória da seleção dos grupos alvos da antipatia, que claramente apresenta bases demográficas e atitudinais específicas, especialmente relacionadas a idade, religiosidade e interesse por política. O nível de tolerância política em relação aos alvos de rejeição, por sua vez, se mostrou mais relacionado a características atitudinais e motivacionais, como a adesão à democracia e o interesse por política.

Como apontamos acima, esses resultados indicam que os achados da literatura internacional se aplicam de forma parcial em nosso contexto, bem diverso em diferentes 
dimensões. Esse exercício comparativo, todavia, é bastante limitado em razão da indisponibilidade de dados nacionais relacionados a importantes condicionantes apontados pelas pesquisas conduzidas nos EUA e países europeus, especialmente ligados a percepção de ameaça e avaliação do potencial dos grupos de desafeição.

Sendo uma análise exploratória sobre a tolerância política entre os brasileiros, nosso artigo abre uma série de caminhos para o desenvolvimento de agendas específicas. Um desses caminhos é a investigação mais detalhada das diferenças geracionais sugeridas pelo efeito da idade em nossos modelos. Da mesma forma, a importância da religiosidade na seleção dos grupos alvo de rejeição e no grau de tolerância merece tratamento mais refinado.

Aproveitando que o instrumento utilizado pelo Lapop incluiu como grupos de referência os simpatizantes ou membros dos dois grandes partidos nacionais, também é possível avançar na investigação sobre o antipartidarismo no Brasil, com ênfase nas atitudes contrárias ao exercício de direitos políticos pelos membros dos partidos. Ainda que a literatura norte-americana e europeia leve em consideração em suas pesquisas apenas os chamados grupos "não conformistas", os dados que apresentamos deixam claro que, em contextos de crise política e polarização política, os grupos convencionais (tais como os partidos políticos) são um dos principais alvos da intolerância. Pesquisas com esse foco temático são relevantes para esclarecer aspectos comportamentais do atual quadro político brasileiro. Esperamos, portanto, que o presente artigo estimule estudos que apostem na tolerância política como uma das chaves de compreensão dos processos e fenômenos políticos hoje em curso em nosso país.

São muitos, portanto, os caminhos possíveis para essa agenda de pesquisas e esperamos que este artigo ofereça uma visão geral e inspiradora para novas investigações que tenham como objetivo aprofundar a compreensão sobre as bases da tolerância política em nossa jovem e instável democracia.

\section{Referências bibliográficas}

Booth, J.; Richard, P. Latin American political culture: public opinion and democracy. Los Angeles: Sage, 2015.

Bоoth, J.; Seligson, M. The legitimacy puzzle: democracy and political support in eight Latin American nations. Cambridge, UK: Cambridge University Press, 2009.

CARLin, R.; Singer, M. "Support for polyarchy in the Americas". Comparative Political Studies, vol. 44, no 11 , p. $1.500-1.526,2011$.

CONVERSE, P. The nature of belief systems in mass publics. In: APTER, D. (org.). Ideology and discontent. New York: The Free Press, 1964.

. Change in the American electorate. In: CAMPBelL, A.; Converse, P. (eds.). The human meaning of social change. New York: Russell, 1972.

Cronbach, L. "Coefficient alpha and the internal structure of tests". Psychometrika, vol. 16, no 3, p. 297-334, 1951. 
CUTLER, S.; KAUfMAN, R. "Cohort changes in political attitudes: tolerance of ideological non conformity". Public Opinion Quarterly, vol. 39, no 1, p. 69-81, 1975.

DALTON, R. Political support in advanced industrial democracies. In: NorRIS, P. (ed.). Critical citizens: global support for democratic governance. Oxford, NY: Oxford University Press, 1999.

. Democratic challenges, democratic choices: the erosion of political support in advanced industrial democracies. New York: Oxford, 2004.

DAVIS, J. "Communism, conformity, cohorts, and categories: American tolerance in 1954 and $1972-$ 1973". American Journal of Sociology, vol. 81, n 3, p. 491-513, 1975.

Delli Carpini, M.; Keeter, S. What Americans know about politics and why it matters. New Heaven: Yale University Press, 1996.

EISENSTEIN, M.; CLARK, A. Heterogeneous religion measures and political tolerance outcomes. In: DJUPE, P. (ed.). Religion and political tolerance in America. Philadelphia: Temple University Press, 2015.

EvANS, G.; Rose, P. "Education and support for democracy in Sub-Saharan Africa: testing mechanisms of influence". Afrobarometer Working Paper 75. Capetown, SA: Afrobarometer, 2007.

FINKEL, S.; ERNST, H. "Civic education in post-apartheid South Africa: alternative paths to development of knowledge and democratic values". Political Psychology, vol. 26, no 3, p. 333-364, 2005.

FUKS, M.; CASAlecchi, G.; ARAúJo, M. "Are dissatisfied democrats critical? Reevaluating the concept of the critical citizen". Opinião Pública, vol. 23, n 2, p. 316-333, 2017.

FuKS, M.; PAULINo, R.; CASALECCHI, G. "Socialization and political regimes: the impact of generation on support for democracy in Latin America". Brazilian Political Science Review, vol. 12, no 1, p. 122, 2018.

FUKS, M., et al. "Qualificando a adesão à democracia: quão democratas são os democratas brasileiros?". Revista Brasileira de Ciência Política, no 19, p. 1.999-1.219, 2016.

GIBSON, J. "Intolerance and political repression in the United States: a half century after McCarthysm". American Journal of Political Science, vol. 52, no 1, p. 96-108, 2008.

Political intolerance in the context of democratic theory. In: Goodin, R. (ed.). The Oxford handbook of political science. Oxford: Oxford University Press, 2009.

GiBSON, J.; DUCH, R.; TEDIN, K. "Democratic values and the transformation of Soviet Union". Journal of Politics, vol. 54, no 2, p. 329-371, 1992.

INGLEhART, R.; WelzeL, C. Modernization, cultural change, and democracy: the human development sequence. New York: Cambridge University Press, 2005.

KLINGEMANN, H. Mapping political support in the 1990s: a global analysis. In: NorRIS, P. (ed.). Critical citizens: global support for democratic governance. Oxford, NY: Oxford University Press, 1999.

LIPSET, S. "Some social requisites of democracy: economic development and political legitimacy". American Political Science Review, no 53, p. 69-105, 1959.

LUSKIN, R. "Explaining political sophistication". Political Behavior, vol. 12, n 4, p. 331-361, 1990.

MARCus, J., et al. With malice toward some: how people make civil liberties judgments. New York: Cambridge University Press, 1995.

MILL, J. On liberty. Lanham, MD: Rowman \& Littlefield Publishers, 2007.

MoIsÉs, J. A. "Cultura política, instituições e democracia - Lições da experiência brasileira". Revista Brasileira de Ciências Sociais, vol. 23, n 66, p. 11-44, 2008.

MoIsÉS, J.; CARNEIRO; G. "Democracia, desconfiança política e insatisfação com o regime: o caso do Brasil". Opinião Pública, Campinas, vol. 14, nº 1, p. 1-42, 2008. 
MoRENO, A.; LAGOS, M. Latin America: the modest dividend of growing up democratic. In: DENEMARK, D., et al. Growing up democratic: does it make a difference? Boulder: Lynne Rienner, 2016.

NeUman, W. R. The paradox of mass politics: knowledge and opinion in the American electorate. Cambridge: Harvard University Press, 1986.

NiE, N.; JUnN, J.; Stehlik-BARRY, K. Education and democratic citizenship in America. Chicago: University of Chicago Press, 1996.

NORRIS, P. Critical citizens: global support for democratic government. Oxford: Oxford University Press, 1999.

NoRRIS, P. Democratic deficit: critical citizens revisited. New York, NY: Cambridge University Press, 2011.

NunN, C.; CrocketT, H.; Williams, J. Tolerance for nonconformity. San Francisco: Jossey Bass, 1978.

Ribeiro, E.; CARreirÃo, Y.; Borba, J. "Sentimentos partidários e antipetismo: condicionantes e covariantes". Opinião Pública, vol. 22, n 3, 2016.

SALinAS, E.; BоотH, J. "Micro-social and contextual sources of democratic attitudes in Latin America". Journal of Politics in Latin America, vol. 3, no 1, p. 29-64, 2011.

SCHEDler, A.; SARSFIELD, R. "Democrats with adjectives: linking direct and indirect measures of democratic support". European Journal of Political Research, vol. 46, p. 637-659, 2007.

SMITH, T., et al. General social surveys: 1972-2014. Chicago: NORC at the University of Chicago, 2016.

Sniderman, P. Personality and democratic politics. Berkeley: University of California Press, 1975.

STENNER, K. The authoritarian dynamics. New York: Cambridge University Press, 2005.

Stouffer, S. Communism, conformity and civil liberties. New York: Doubleday, 1955.

Sullivan, J.; Piereson, J.; Marcus, G. Political tolerance and American democracy. Chicago: University of Chicago Press, 1982.

Sullivan, J., et al. Political tolerance in context. Boulder, Co.: Westview Press, 1985.

Verba, S.; SCHLOZMAn, K.; BRADY, H. Voice and equality: civic voluntarism in American politics. Cambridge, Mass.: Harvard University Press, 1995.

\begin{abstract}
Political tolerance in Brazil

Understanding political tolerance as one of the dimensions of a democratic political culture, the article uses a set of unpublished data produced by the Latin American Public Project to exploratively compose a general picture of this attitude in the national context. Using descriptive and multivariate analysis techniques, we identify the main groups that are the targets of Brazilian antipathy and determine the degree of tolerance towards them as well as their demographic and attitudinal bases. The results indicate that the manifestation of tolerance is a function of both social attributes (such as generation) and attitudinal ones (such as adherence to democracy and interest in politics), pointing the way to a broad agenda for future studies on the subject.
\end{abstract}

Keywords: political tolerance; antipathy target groups; Brazil 


\section{Resumen}

Tolerancia política en Brasil

Entendiendo la tolerancia política como una de las dimensiones de una cultura política democrática, el artículo utiliza un conjunto de datos inéditos producidos por el Proyecto Público Latinoamericano para componer de manera exploratoria una imagen general de esta actitud en el contexto nacional. Mediante técnicas de análisis descriptivo y multivariado, identificamos los principales grupos que son el objetivo de la antipatía brasileña y el grado de tolerancia hacia ellos, así como sus bases demográficas y de actitud. Los resultados indican que la manifestación de la tolerancia es una función de los atributos sociales (como la generación) y actitudinales (como la adhesión a la democracia y el interés en la política) y apunta a una amplia agenda de futuras investigaciones sobre el tema.

Palabras clave: tolerancia política; grupos blanco de antipatía; Brasil

\section{Résumé}

Tolérance politique au Brésil

Comprenant la tolérance politique comme l'une des dimensions d'une culture politique démocratique, I'article utilise un ensemble de données non publiées produites par le Projet Public Latino-américain pour constituer de manière exploratoire un tableau général de cette attitude dans le contexte national. À l'aide de techniques d'analyse descriptive et multivariée, nous avons identifié les principaux groupes cibles de l'antipathie brésilienne et leur degré de tolérance à leur égard, ainsi que leurs bases démographiques et comportementales. Les résultats indiquent que la manifestation de la tolérance est une fonction à la fois d'attributs sociaux (tels que la génération) et d'attitudes (telles que l'adhésion à la démocratie et l'intérêt pour la politique) et indique un vaste programme d'enquêtes futures sur le sujet.

Mots-clés: tolérance politique; groupes cibles de l'antipathie; Brésil

Artigo submetido à publicação em 23 de agosto de 2018. Versão final aprovada em 8 de agosto de 2019.

Opinião Pública adota a licença Creative Commons CC-BY. 